\title{
Personal Moral Philosophy of Undergraduates towards Academic Dishonesty
}

\author{
Jeffrey Lawrence D‘Silva ${ }^{1}$, Chan Ling Meng ${ }^{2} \&$ Jamilah Othman $^{1}$ \\ ${ }^{1}$ Institute for Social Science Studies, Universiti Putra Malaysia, Serdang, Malaysia \\ ${ }^{2}$ Department of Business, Faculty of Business and Finance, University Tunku Abdul Rahman, Kampar, Malaysia \\ Correspondence: Jeffrey Lawrence D'Silva, Institute for Social Science Studies, Universiti Putra Malaysia, \\ 43400 UPM Serdang, Selangor, Malaysia. Tel: 603-8947-1862. E-mail: jld@upm.edu.my
}

Received: May 14, 2015

Accepted: July 3, 2015

Online Published: September 30, 2015

doi:10.5539/mas.v9n11p144

URL: http://dx.doi.org/10.5539/mas.v9n11p144

The research is financed by Research Management Centre, Universiti Putra Malaysia.

\begin{abstract}
Undeniably moral belief among undergraduates is pertinent since it will provide a better perspective to seek for answers on the possible reasons undergraduates engage in unethical behaviour. However, the existing literature showed that only limited studies focuses in this specific moral belief development of undergraduates. Thus, this study aimed to identity the level of personal moral philosophy (idealism and relativism) of undergraduates together with the examination on the relationship between PMP and undergraduates' academic cheating behaviour. Data were collected from 620 undergraduates through questionnaire surveys by employing a simple random sampling. The study found that undergraduates are lately more idealism compared to relativism, which indicated that students are aware with the academic cheating behaviour and try to avoid involving in it. Future recommendations are provided to further understand the complexities associated with academic dishonesty.
\end{abstract}

Keywords: undergraduates, academic dishonesty, personal moral philosophy

\section{Introduction}

Due to the disturbing economic conditions, significant number of students, reluctant or unable to enter a volatile job market, has enrolled in college and university - to obtain competitive skills and improve the chance for future employment. This unethical behaviour students develop in academia will likely translate to unethical behaviour in the workplace (Pottle, 2012). In the universities, undergraduates are aware of the wrongdoing of their peers, however, this caused them face tough ethical dilemma. Either they face the wrongdoers directly, persuade them to change objectionable behaviour, or, just walk away from this dilemma. This has explained in the study of Ho, Vitell, Barness \& Desborde (1997), that moral reasoning has significant influence an individual's ethical behaviour. The decision to act academic cheating is an ethical dilemma that faced by most undergraduates, hence a moral component may be critical in such decision. This can be explained the reason why students still cheat in their study, even though they have been educated for this issues since in primary school. In universities, it has a particular influential effect on gains in moral reasoning scores, where they may be significant differences in this moral component according to the universities level. Opportunities to participate in discussion of differing moral perspectives are not often provided in an undergraduate program, so there may be differences in the relative influence of a moral component by discipline. Shaw (2008) acknowledged that morality initially take place when we are child, from their own inner feeling, which subsequently translates into his / her moral behaviour. Individual learns to adapt the ethical principles through his / her upbringing, socialization, experiences and critical reflection on those experiences together with the explicit and implicit standards of culture.

Hence, it suggested that in order for us to shape up a morally high based culture in the working world, we should start to educate and guide students, especially undergraduates who are going through 3 to 4 years of learning development before they step into another stage of life. Thus, this study we place the focus on the characteristics of undergraduates in Malaysia, mainly on their typology of moral philosophy. Moral belief among undergraduates is important for researchers to study as it will help us to understand better the rationale behind them to engage in some unethical behaviour, as such academic cheating behaviour (cheat in exam, gives fraud $\mathrm{mc}$ etc). However, 
limited studies have focused in this specific moral belief development of undergraduates. Hence, the following research objectives are proposed:

1. To identify the level of personal moral philosophy (idealism and relativism) of undergraduates;

2. To identify the types of personal moral philosophy of undergraduates; and

3. To examine the relationship between the personal moral philosophy and undergraduates' academic cheating behaviour

The paper is presented with a review of past studies on academic cheating behaviour and personal moral philosophy, followed by the review on past studies of relationship between the personal moral philosophy with academic cheating behaviour. It followed by the discussion on research methodology, research analysis method and sampling size. The results of the study will be presented after this section. Last but not least, the discussion and conclusion of the study will be at the last section of this paper. These include the implications of the study and future recommendation.

\section{Literature Review}

\subsection{Academic Dishonesty}

Academic dishonesty is defined as violation of rules and regulations in most tertiary education institutions (Symaco \& Marceb, 2003). They acknowledge such unethical act is a chronic constraint that has successfully escaped a lasting solution regardless of institutional efforts to eradicate it. Furthermore, they also acknowledged that undergraduates nowadays tended to perceive such immoral act as a normal and common practice, especially among their peers group. Petress (2003) noted the types of academic misconduct such as copying test responses from a classmate; taking exam for friends; failure to cite other people work; taking exam home and purchasing research papers and one assumes it is his / her work; breaking the office or teachers' file to access the test or answer key; sabotaging peers ongoing work or gaining illegal access to school computer to change official grades. In addition, plagiarism is also one of the newly raising type of academic dishonesty where individuals tended to manipulate the data in favour of what they want to achieve.

Besides that, academic dishonesty is also known as student's deviant behaviour, as it will result negatively to the development of students' characteristics and personality traits (Staats, et al, 2009). This deviant behaviour may result in jeopardy to the integrity of academic for each learning institutions. Academic cheaters may place their personal aims over others, and this may harm others, especially the peer group.

In the study of Dichtl (2003), he acknowledged that academic dishonesty is learned behaviour, from the observation of peers, and this immoral act will causes unsecure among those honesty students. Passow et al (2006) further acknowledged this immoral act will jeoparding the validity of learning process of undergraduates. This may effects the academicians fail to acknowledge and recognized the acceptance of students towards their study. In addition, it also causes academicians failed to recognize the effort from the students due to this unethical act. Robert (2002) suggested that reasons students engaged in such immoral act mainly due to insufficient of time for revisions, unable to understand the subjects well, peer influences, afraid of failure and technology advancement.

\subsection{Personal Moral Philosophy}

Personal moral philosophy (PMP) is defined as a set of moral belief, values and attitude, which may affect individuals' judgment and decision making, especially involve in ethical dilemmas (Chan, Othman, \& Jones, 2011). Forsyth (1980) explained that PMP contains the distinctive elements produced by previous experiences in confronting ethical dilemmas (Chan, Othman and Joned, 2011). The definition of PMP is further enhance by Henle, et a (2005: 219) as an ethics system serves as ethical guidelines in making ethical judgmental decision. Through this system, it able to assist individuals in resolving ethical dilemmas accordingly based on their own moral belief. This indicates that personal moral philosophy maybe one of the crucial mechanisms where organizations can identify which employees will involve in immoral behavior. It is able to reduce the occurrence of socially unethical behaviour in the workplace, by understanding and controlling this ethical mechanism.

Forsyth (1980) proposed that personal moral philosophy contains two different dimensions: Idealism and Relativism. Idealism dimension describes individuals' attitude toward his / her ethical action, and how this ethical consequences will bring the impact to others' wellbeing. Forsyth (1992) proposed that a highly idealist will have the belief that this ethical action should and must bring a positive consequences to everyone. High idealism individuals tended to avoid in unethical action, as they believe that this is morally wrong act and it may bring significant harms to others. While those individuals who have lower idealism tended to be programmatic in 
their ethical orientation towards consequences and believe that sometimes it is necessary to have some negative consequences in order to bring the greatest benefits to the parties involved. (Forsyth and Nye, 1990; Forsyth, 1992)

While the dimension of relativism indicates individuals tended to reject the universal moral principles (Forsyth, 1980). Forsyth (1992) suggested that individuals who have high relativism tended to hold the belief that an action's morality is rely on the particular circumstances involved. However, low relativism tend to rely heavily on the universal moral principles when evaluating the ethically of an action.

Forsyth \& Nye (1990) proposed that due to the different levels of idealism and relativism, it created a four different typology of personal moral philosophy (See Table 1). The concept of this has produced 2 x 2 taxonomy of personal moral philosophy.

Table 1. Matrix of Personal Moral Philosophy

\begin{tabular}{lll}
\hline \multicolumn{2}{c}{ Relativism } & \\
\hline Idealism & High & Low \\
High & $\begin{array}{l}\text { Situationist: } \\
\text { Reject moral rules and review the } \\
\text { circumstances of a given situation to } \\
\text { determine the appropriate action. }\end{array}$ & $\begin{array}{l}\text { Apply universal moral rules to achieve the } \\
\text { best possible outcome. }\end{array}$ \\
Low & $\begin{array}{l}\text { Subjectivist: } \\
\text { Use personal value and opinion to } \\
\text { solve ethical issue raised. }\end{array}$ & $\begin{array}{l}\text { Apply with moral judgments in pragmatic way } \\
\text { and are willing to accept exceptions to these } \\
\text { rules even if bad consequences ensue. }\end{array}$ \\
\hline
\end{tabular}

There are four different typology of personal moral philosophy based on different levels of idealism and relativism respectively. Individuals who scored both high in relativism and idealism is known as situationist. This type of individual holds the belief that people should have the intention to produce positive and morally right consequences. He / she tends to reject the moral rules applications in various situations. They believe that in different situations, they may need to apply different ways of ethical action in order to get the ethically right consequences.

While absolutist (individuals who are highly idealism but relatively low in relativism) has different ethical opinions compare with situationist. They hold the blief that ethical behaviour will bring positive consequences with conformity with universal moral principles.

Individual who have high relativism but relatively low in idealism is known as subjectivist. This type of individual use their own personal value and opinion to solve ethical issue raised. They tended to reject the universal moral belief where negative consequences does not mean will causes immoral act.

Exceptionists believe that it is desirable to accept moral absolutes, with some exceptions to different standards. This suggested that it is not necessary an action will be condemned due to its' negative consequences for some people.

\subsection{Past Studies of Personal Moral Philosophy on Academic Cheating Behaviour}

Forsyth (1980) proposed that different scoring in idealism and relativism will result in different ethical typology when facing ethical dilemma. These result different conclusions based on the morality of certain action. Lin $\&$ Ding (2003) further acknowledged that different typology of moral philosophy will make individuals judge an ethical action based on their own perspectives. This will lead to different degree of sensitivity to wrongdoing behaviour.

Forsyth and Nye (1990) pointed that idealist are strongly concerned for others' wellbeing, and most evaluate possible negative consequences on others due to the unethical behaviour. They tended to consider this unethical behaviour as highly unethical when it has potential harm to the organization.

While, relativists hold the belief that it is impossible to make morally right action, without knowing possible circumstances, hence relativists tended less likely to engage in academic cheating behaviour (Forsyth \& Nye, 1990; Lin \& Ding, 2003).

Non - relativist individual were less likely than relativist to violate a societal norm for personal gain. This raises 
the possibility that relativists may be more inclined than non - relativist to engage in self - beneficial unethical behaviour, and are less likely to report such behaviour of peers. Consequently, relativism is negatively linked with judging peer reporting as ethical (Forsyth \& Nye, 1990; Lin \& Ding, 2003)

Past researchers acknowledged that there were mixed results in the examination of the relationship between ethical ideologies and ethical behaviours. Mullin - Marta et al (2003)'s findings suggested that personal moral philosophy of students would diverge as indicated by differences in their idealism and relativism score. This is further acknowledged in the study of Wilson (2003), where his findings showed that ruthless individuals can be indifferent to ethical issues when seeking their personal goals.

Most of the past studies suggested that there is a relationship exists between the ethical ideologies and academic misconduct. Such as result of Cohen (2001) suggest that individual's ethical behaviour with low relativism was found to be lower than the individual with high idealism score. This is consistent with the findings of Cruz et al (200), that there was strong relationships exist between an individual's ethical ideologies and his / her ethical behaviour, and a positive relationship exists between the intent to behave ethically and justice.

However, these results were inconsistent with the study of Shaub et al (1993) where they pointed that there was a negatively relationship between ethical ideologies and ethical behaviour. This was strengthened by Chan \& Leung (2006) that there was a weak relationship found between ethical ideologies and ethical behaviour. However, in the latest study of Emerson et al (2007)'s findings showed that there was a significant relationship between individual's ethical ideologies and their ethical behaviour.

In the study of Singhapakdi and his friends (2000), they concluded that there was a significant relationship between idealism and ethical ideologies. This is consistent with the result of May and Pauli (2002), where there was a positive relationship within the idealism dimension and ethical awareness, respondents tended to be more sensitive as their idealism score increases. In addition, in the study Davis et al (2001), they stated that idealism scale was shown to be a significant predictor of ethical behaviour in five different scenarios.

Respondents with high idealism score tended to be morally opposed to actions potentially harmful to others. Moreover, relativism scale was found to play primarily a mediating role in the relationship between idealism and the formation of ethical behaviour. Besides that, in their study, they also acknowledged that both scale of idealism and relativism were founded to be correlated. Consistently, in the findings of Barnett, Bass and Brown (1996), they concluded that students who scored high in idealism and low in relativism were more inclined to view reporting a peer's cheating as ethical action.

While in the dimension of relativism, findings of Sparks \& Hunt (1998) and Yetmar \& Estman (2000)' s suggested that there was a negative relationship between relativism and ethical behaviour. They suggested that ethical behaviour decreases as relativist orientation increase; hence it causes unethical behaviour to increase. They concluded that absolutist were found to be the most ethical while subjectivist are the least so in their ethical behaviour. Absolutist tended to act stricter than both subjectivist and Exceptionist. This is similar with the study of Tansey, Brown, Hyman \& Dawson (1994), where they also agreed that absolutist were the strictest in terms of their ethical behaviours, while subjectivist were the most lenient.

\section{Methodology}

Simple random sampling techniques were adopted in this study. Undergraduates were sampled based on the overall population of undergraduates in each university. The population was further stratified according to different universities at different locations in Malaysia. Researchers used snowball sampling technique in this study, due to the unavailability of sample frame from which an accurate sample size could be drawn

This study consists of sample size 620 undergraduates, from six different universities in Malaysia. Majority of respondents aged 19. 49.8 percent are male respondents and 50.2 percent are female respondents. Respondents come from two different main stream of study, Business $(\mathrm{n}=322)$ and Science (298).

In this study, an adaption of questionnaires was used to look for the findings for the research objectives. The questionnaire was divided into three different sections. Section A consists of item on evaluating students' frequency in engaging activities of academic dishonesty. There are twenty five items on the activities involved academic cheating, such as cheating in the exam, plagiarizing other work as own, and giving fraud mc during exam, helping peers in sitting exam etc. Section B is the questionnaire of Ethics Position Questionnaire (EPQ), adopting from the Forsyth (1980) with some amendments according to Malaysia' culture and values. There are twenty items to examine the level of idealism and relativism respectively in this questionnaire. While section $\mathrm{C}$ consists of demographic profile of respondents. 7 point Likert scale was used in this study, with 1 indicating strongly disagree and 7 indicating strong agree. 
The score of academic cheating behaviour were examined by calculating the mean score of the answers. The higher mean score indicate the higher frequency undergraduates engaging in academic dishonesty behaviour. While for the score of personal moral philosophy, it has two different score for two different dimensions: Idealism and Relativism. For the score in idealism, score was calculated the mean from item 1 to item 10; while relativism is from the item 11 to item 20 . Higher scores in both dimensions of idealism and relativism suggest higher levels of idealism and relativism. In order to group the undergraduates into four different types of personal moral philosophy, idealism and relativism score were using based on the median scores as cut off point respectively. The median scores for idealism is 45 and relativism is 47 . A scale of between 45 and above is considered high for idealism and relativism, while any score below 45 will be considered low for both subscales. From the different level of idealism and relativism, there are four different types of personal moral philosophy in the findings

\section{Results and Discussion}

4.1 RO 1: To Identify the Level of Personal Moral Philosophy (Idealism and Relativism) of Undergraduates

Table 2. Descriptive Statistics of Idealism, Relativism and Academic Cheating Behaviour of Undergraduates

\begin{tabular}{lllll}
\hline Variables & $M, \overline{\mathrm{x}}$ & Median, $M d$ & Std. Deviation, & $\hat{\mathrm{s}}$ \\
\hline Academic Cheating Behaviour & 4.11 & 1.92 & .79 \\
Relativism & 4.79 & 4.70 & 1.17 \\
Idealism & 4.59 & 4.50 & 1.09 \\
\hline
\end{tabular}

From Table 2, it showed the descriptions of the variables tested. Mean score for academic cheating behaviour is $(\mathrm{M}=4.11)$, with $\mathrm{SD}=.79$. This suggested that most of undergraduates most likely to engage in academic cheating activities, ranging from cheating in exam, plagiarism in their assignment or giving fraud $\mathrm{mc}$ etc. This is further strengthened by higher relativism score among them compare with idealism score. From Table 1, it showed that most of undergraduates score higher in their relativism $(\mathrm{M}=4.79, \mathrm{SD}=1.17)$ while compare with their idealism $(\mathrm{M}=4.59 ; \mathrm{SD}=4.50)$. It suggested that undergraduates hold relativism orientations, which hold the belief that trying to get extra assistance in their academic journey is ok, as long it does not bring any harm to themselves or others. It showed that most of undergraduates are not aware with the consequences of academic cheating behaviour. That why it explained why they tended to involve in such unethical act. The lower scoring in idealism among undergraduates suggested that undergraduates accept universal principles when making ethical judgments, especially when they encounter ethical dilemma.

\subsection{RO 2: To Identify the Types of Personal Moral Philosophy of Undergraduates}

Table 3. Descriptive Statistical on Type of Personal Moral Philosophy of Undergraduates

\begin{tabular}{lll}
\hline Types of PMP & \multicolumn{2}{l}{ Gender $(\mathrm{n}=620)$} \\
\cline { 2 - 3 } & Male & Female \\
Situationist $(\mathrm{n}=263)$ & 138 & 125 \\
Absolutist $(\mathrm{n}=61)$ & 31 & 30 \\
Subjectivist $(\mathrm{n}=61)$ & 20 & 41 \\
Exceptionist $(\mathrm{n}=235)$ & 120 & 115 \\
\hline
\end{tabular}

From Table 3, it describes the types of personal moral philosophy of undergraduates based on gender and study stream. Majority of students have the characteristics of Situationist $(n=263)$, followed by Exceptionist $(n=235)$ and the least number of students possess the characteristics of Subjectivist or Absolutist $(n=61)$ respectively. From the data analysis, it indicates that most of respondents consist of different types of personal moral philosophy. The highest number of PMP undergraduates have is situationist, which they tended to advocates a contextual analysis of morality questionable actions. Forsyth (1980) suggested that situationist tended to make ethical decision making based on the situation, rather based on their own characters. This is significant explained why different individual will have different behaviour in a similar situation. In one person's view that sharing 
information with peer during exam is ok compare another who perceived it as unethical behaviour. These types of undergraduates tended to endorses an ideology related to moral philosophy. These suggested that there are varies of definition on the morality of an act. Individuals with such characteristics may hold the belief that there are no moral principles are valid except in reference to one's own behaviour; moral evaluation must ultimately depend on personal perspectives.

It is followed by exceptionist, which admits that exceptions must sometimes be made to moral absolutes. Exceptionist is the type of individual who believe action's morality is rely on the consequences of such act. Undergraduates with such personality tended to perceived that an ethically right action is an action that can produces "good" "harmless" consequences, which make them think that helping each other in order to get a good grade in examination is a morally right action, as it brings the greatest good for the greatest number. Exceptionist undergraduates believe that absolute moral principles are important, however, they must apply these rules pragmatically.

Meanwhile, through the findings, it showed that there are 61 absolutist undergraduates, tended to argue individuals' personal values defined the moral judgment. Absolutists are the individuals who agree with statements that are consistent with deontology. They believe that moral acts are required to follow strictly. Forsyth (1980) furthered explained, with such belief, it implies that professionals' proposed course of action (which adversely affects the project quality, cost and time) that is not widely acceptable or that cannot be seen as a universal law that applies to all professionals in all situations at all time, is unethical.

While for subjectivist, they make evaluation based on their personal values and belief rather than common moral rules. Subjectivist tended to be relativistic, as they only look at their own personal value rather than any other moral value. These types of undergraduates tended to believe that as long they think what they carry out is fulfilling their own moral judgment, others view are not important.

From Table 1, it also indicated that most male and female undergraduates possess the characteristics of Situationist ( $\mathrm{n}=138, \mathrm{n}=125$ respectively). However, less number of male and female undergraduates have the characteristics of Subjectivist ( $\mathrm{n}=20, \mathrm{n}-41$ respectively). Based on the study stream of undergraduates, it showed that majority business majoring undergraduates have the characteristics of Exceptionist $(n=135)$. This can explained why most of academic cheating behaviour occurred among business student, as they want to help each other to get good result. While, most majoring humanities undergraduates possess the characteristic of Situationist $(\mathrm{n}-133)$. These is further strengthened the personal characteristics of humanities student, which they are more focusing on their own behaviour, rather than others

\subsection{RO3: To Examine the Relationship Between the Types of Personal Moral Philosophy and Undergraduates' Academic Cheating Behaviour}

In order to examine the relationship of PMP typology with academic cheating behaviour, One Way ANOVA was used to analyze. Table 4 is ANOVA Table, which shows the output of the ANOVA analysis and whether there is a statistically differences between the types of personal moral philosophy of undergraduates in academic cheating behaviour. From the significant level, it showed $.000(\mathrm{p}=.000)$ which is below .05 , therefore, we can conclude that there is a statistically significant different between the mean of academic cheating behaviour between the different types of personal moral philosophy among undergraduates.

Table 4. One-way ANOVA

\begin{tabular}{lllllc}
\hline & Sum of Squares & df & Mean Square F & Sig. \\
\cline { 2 - 6 } Between Groups & 11.474 & 3 & 3.825 & 6.475 & .000 \\
Within Groups & 363.865 & 616 & .591 & & \\
Total & 375.339 & 619 & & & \\
\hline
\end{tabular}

Table 5 is the Multiple Comparison table which showed the significant differences between groups as a whole. From Table 3, it showed that there are significant differences between the situationist undergraduates and subjectivist undergraduates $(p=.023)$, situationist undergraduates with exceptionist undergraduates $(p=.001)$ in their mean of academic cheating behaviour. However, there were no differences between the situationist undergraduates with subjectivist $(\mathrm{p}=.38)$ 
Table 5. Multiple Comparisons

\begin{tabular}{llllll}
\hline (I) Type of PMP(J) Type of PMPMean DifferenceStd. & \multicolumn{3}{c}{ Sig. } & \multicolumn{3}{c}{ 95\% Confidence Interval } \\
& & $(\mathrm{I}-\mathrm{J})$ & Error & $\begin{array}{r}\text { Lower } \\
\text { Bound }\end{array}$ & $\begin{array}{l}\text { Upper } \\
\text { Bound }\end{array}$ \\
\hline \multirow{4}{*}{ Situationist } & & & .10922 .023 & -.5929 & -.0302 \\
& Absolutist & $-.31158^{*}$ & $.109221 .000-.2808$ & .2819 \\
& Subjectivist & .00056 & .06899 .001 & -.4378 & -.0824 \\
& Exceptionist & $-.26011^{*}$ & .10922 .023 & .0302 & .5929 \\
& Situationist & $.31158^{*}$ & .13916 .113 & -.0464 & .6706 \\
& Subjectivist & .31213 & .11044 .966 & -.2330 & .3360 \\
& Exceptionist & .05146 & $.109221 .000-.2819$ & .2808 \\
& Situationist & -.00056 & .13916 .113 & -.6706 & .0464 \\
& Absolutist & -.31213 & .11044 .086 & -.5452 & .0238 \\
& Exceptionist & -.26067 & .06899 .001 & .0824 & .4378 \\
& Situationist & $.26011^{*}$ & .11044 .966 & -.3360 & .2330 \\
& Absolutist & -.05146 & .11044 .086 & -.0238 & .5452 \\
\hline
\end{tabular}

Moreover, through the findings it further enhanced that the relationship between moral belief and moral behaviour are related. This is consistent with past studies (Pottle, 2012, Stone et al, 2010 etc) that proposed that personal moral philosophy is an attribution style that outlook on life dimension rather than an attitude towards a specific issues. Personal moral philosophy predisposes some individuals toward involvement in social causes and virtually inoculates others from this type of involvement. However, most studies focussed more on the universities and college undergraduates. Future studies may consider the examination on the ethical paradigms of individuals who having unusually high levels of commitment to social and moral issues.

\section{Conclusion}

Note that this study was not attempted to directly compare the moral characteristics of undergraduates and differentiate them which is the best students or which is the bad students. This study attempted to understand the rationale of why undergraduates take certain particular stances regards this ethically action and that the position taken will influence the judgment reached. From the findings, we can concluded that most undergraduates nowadays are more idealism compare to relativism, which indicated that students are aware with the academic cheating behaviour and try to avoid involving it. That why the frequencies of cheating behaviour among them were relatively low compared to other studies in the past. However, we may need to further investigate the cognitive rationale of them in engaging academic cheating behaviour, as this study indicates that awareness of them are high, but why they still want to cheat?

An experimental study with the same students is proposed for future studies, in order to yield more information on their moral evolution through the study in universities. Besides that, future research may need to consider in segregate the business majoring undergraduates into functional areas, like accounting, marketing, finance etc. in order to have a better comparison on the attitude and perceptions regarding the personal moral philosophy and academic cheating behaviour.

Based on the findings, it showed that education of morality should not paying attention on how to identify the unethical act, but it would be better to place more focus on the immoral act behaviour in both academic and business setting. As academicians and faculty members in universities, they need to be more vigilant in its efforts at solving academic cheating behaviour. Constant reminders to be commence before exam take place together with the serious action to be taken against cheater. This will be able to reduce the intention of students to cheat during examination. Furthermore, clear communication on goal expectation and constant feedback on students' performance also able to reduce the frequency of students engaging in academic cheating behaviour. Academicians and faculty members should not only emphasize on the strict rule and harsh punishment in curbing this unethical act. They should have a proper channel of communication to guide students accordingly in handling this immoral act. Students must constant educate on the consequences of unethical act during their study period. 
As academicians, we should not wait until students act unethically in their future workplace, and then only we start to deter, detect and punish them as working adult. We should start to educate and increase their awareness in academic integrity. Most of the past studies (Ho \& Redfern, 2010; Pottle, 2012, Kujala, Lämsä, \& Penttila, 2011 etc) are more focusing on the typology of moral philosophy among working marketing executive, sales manager, business manager etc, instead looking at the population of undergraduates who are going to enter the working world soon. As researchers, we believe that in order to avoid this unethical epidemic in getting more serious, we should place more focuses on the moral development of undergraduates. We should not wait until the students involve in unethical activities in their future workplace, then only we start to think about ways to deter, detect and punish them harshly. It is proper for us to educate our students during their university time, and guide them accordingly by sharing the consequences of such unethical behaviour in the workplace and the hurt to the nation development.

\section{Acknowledgments}

The authors would like to express their gratitude to the Research Management Centre, Universiti Putra Malaysia for sponsoring the study. Besides, special thanks to the enumerators of this study for their vast contribution in the data collection process.

\section{References}

Chan, C. L. M., Othman, J., \& Joned, R. (2011). The Conceptual Model of Personal Moral Philosophy (PMP) and Ethical Decision Making (EDM). Journal of Management Research, 3(2).

Chan, S. Y. S., \& Leung, P. (2006). The effects of accounting students' ethical reasoning and personal factors on their ethical sensitivity. Managerial Auditing Journal, 21(4), 436-457.

Cohen, J. (2001). Social emotional education: Core principles and practices. In J. Cohen (ed.), Caring classrooms/intelligent schools: The social emotional education of young children (pp. 3-29). New York: Teachers College Press.

Cruz, J. A., \& Frey, W. J. (2001). Ethics and empowerment: An ethics module for introduction to computers. Paper presented at the ASEE Annual Conference and Exposition, Albuquerque, New Mexico.

Davis, M. A., Andersen, M. G., \& Curtis, M. B. (2001). Measuring ethical ideology in business ethics: A critical analysis of the ethics position questionnaire. Journal of Business Ethics, 32, 35-53.

Emerson, T., Conroy, S. \& Stanley, C. (2007). Ethical attitudes of accountants: Recent evidence from a practitioners' survey. Journal of Business Ethics, 71, 73-87.

Forsyth, D. R. (1980). A Taxonomy of Ethical Ideologies. Journal of Personality and Social Psychology., 39, 175-184.

Forsyth, D. R. (1992), Judging the Morality of Business Practices: The Influence of Personal Moral Philosophies', Journal of Business Ethics, 11, 461-470.

Forsyth, D. R., \& Nye, J. L. (1990). Personal moral philosophies and moral choice. Journal of Research in Personality, 24, 398-414.

Ho, C., \& Redfern, K. A. (2010). Consideration of the role of guanxiin the ethical judgments of Chinese managers, Journal of Business Ethics, 96, 207-221. http://dx.doi.org/10.1007/s10551-010-0459-4

Ho, F. N., Vitell, S. J., Barnes, J. H., \& Desborde, R. (1997). Ethical correlates of role conflict and ambiguity in marketing: The mediating role of cognitive moral development. Journal of the Academy of Marketing Science, 25(2), 117-126.http://dx.doi.org/10.1007/BF02894347

Kujala, J., Lämsä, A. M., \& Penttila, K. (2011). Managers' moral decision-making patterns over time: Amultidimensional approach, Journal of Business Ethics, 100, 191-207. http://dx.doi.org/10.1007/s10551-010-0467-4

Lin, C. P., \& Ding, C. G. (2003). Ethical Ideology, Subjective Norm, and Peer Reporting Intentions using An Individual - Situation Moderator. Asia Pacific Management Review, 8(3), 311-335.

Shaw, W. H. (2008). Business Ethics (6th ed.). Belmont, CA: Thompson Wadsworth.

Singhapakdi, A., Salyachivin, S., Virakul, B., \& Veerayangkur, V. (2000). Some important factors underlying ethical decision making of managers in Thailand. Journal of Business Ethics, 27, 271-284.

Tansey, R. G., Brown, G., Hyman, M., \& Dawson, L. (1994). Personal moral philosophy and moral judgments of sales person. Journal of Personal Selling and Sales Management, 14(1), 59-76. 
Wilson, J. F. (2003). The crucial link between literacy and health. Annals of Internal Medicine, 139, 875-878.

\section{Copyrights}

Copyright for this article is retained by the author(s), with first publication rights granted to the journal.

This is an open-access article distributed under the terms and conditions of the Creative Commons Attribution license (http://creativecommons.org/licenses/by/3.0/). 